\title{
Hydrocarbon refrigerant charge limits for quiescent rooms
}

\author{
D. Colbourne ${ }^{(a)}{ }^{*}$, K. O. Suen ${ }^{(b)}$ \\ (a) Re-phridge, c/o HEAT GmbH/GIZ Proklima \\ (b) University College London, Gower Street, London, WC1E 6BT, UK
}

\section{Highlights}

- Examined release and dispersion of R290 into a closed room, accounting for unit characteristics under quiescent conditions

- Shown relationship between room floor concentration and that of the mixture exiting an enclosure from wherein a release has emanated

- Proposed a new allowable charge calculation based on flammability limits, enclosure characteristics and release conditions

- Considered various types of enclosures, applicable to air conditioners, refrigeration appliances and heat pumps 


\begin{abstract}
Concentration measurements and analysis have been used to develop new methodology for estimating the allowable charge limit (ACL) of flammable refrigerants, particularly R290. Attention has been given to the impacts of construction and dimensional characteristics of the RACHP enclosures, in particular the size and position of the openings, on the concentrations exiting the enclosure. Analysis of the data has shown that these are critical aspects that influence floor concentration and/or safe allowable refrigerant charge limits. Formulae have been proposed to estimate layer-volume heights and ultimately ACL. The results illustrate that current standard's ACLs are overly restrictive, especially for certain types of RACHP equipment.
\end{abstract}

\title{
Keywords:
}

Hydrocarbon refrigerant, flammable refrigerant, safety, allowable charge limits, R290, propane

* Corresponding author; Tel: +44 1789268 285; email: dc@ re-phridge.co.uk

\section{Nomenclature}

\begin{tabular}{|c|c|}
\hline$A$ & floor area $\left[\mathrm{m}^{2}\right]$ \\
\hline $\mathrm{AC}$ & air conditioner \\
\hline ACL & allowable charge limit \\
\hline$C_{\text {floor }}$ & floor concentration $\left[\mathrm{g} \mathrm{m}^{-3}\right]$ \\
\hline $\bar{C}_{\text {floor }}$ & average floor concentration $\left[\mathrm{g} \mathrm{m}^{-3}\right]$ \\
\hline$C_{\text {exit }}$ & maximum exiting concentration $\left[\mathrm{g} \mathrm{m}^{-3}\right]$ \\
\hline EN & European norm \\
\hline$F_{L F L}$ & an adjustment factor applied to the LFL [-] \\
\hline $\mathrm{HCP}$ & height-concentration profile \\
\hline$h^{*}$ & representative height of the refrigerant layer-volume inside the room [m] \\
\hline$h_{\text {base }}$ & height of the base of the enclosure $[\mathrm{m}]$ \\
\hline$h_{\text {lower,top }}$ & height of top edge of the lower opening [m] \\
\hline$h_{\text {lower,bot }}$ & height of bottom edge of the lower opening [m] \\
\hline$h_{o}$ & enclosure opening size, i.e. $h_{\text {lower,top }}-h_{\text {lower, bot }}$, for a given width [m] \\
\hline$h_{\text {rel }}$ & height of the refrigerant release $[\mathrm{m}]$ \\
\hline IDUE & indoor unit enclosure \\
\hline IEC & international electrotechnical commission \\
\hline LFL & lower flammability limit $\left[\mathrm{g} \mathrm{m}^{-3}\right]$ \\
\hline$m_{A C L}$ & allowable charge limit $[\mathrm{kg}]$ \\
\hline RACHP & refrigeration, air-conditioning and heat pump \\
\hline VE & variable enclosure \\
\hline
\end{tabular}




\section{Introduction}

Current allowable charge limits (ACL) prescribed within safety standards for using class A3 refrigerants in closed indoor spaces are considered to be too restrictive - in terms of grams permitted per unit of room floor area - to enable wider application of these low GWP refrigerants (Colbourne et al., 2020a) and as such need to be revised. This demands further examination of the dispersion of refrigerants in closed spaces, the influencing characteristics of equipment and the development of more flexible rules. Since the publication of earlier editions of EN 378 and IEC 60335-2-40 there have been discussions on ACL, including those of Kataoka et al. (2000) and Colbourne and Suen (2003) on such formulae. Kataoka et al. made assumptions about the condition of the leaked refrigerant entering the room from the air conditioning (AC) indoor unit enclosure (IDUE), where it was argued that the release is of pure refrigerant at very low velocity emerging from the IDUE. These, along with other assumptions resulted in stringent ACL formulae in that only a limited amount of A3 refrigerant was permitted (e.g., Colbourne et al., 2020a). Other work (e.g. Jabbour and Clodic, 2008; Zhang et al., 2013; Li, 2014) involving measurements of room floor concentrations $\left(C_{\text {floor }}\right)$ due to releases of R290 (propane) from AC units were shown to be significantly lower than what was inferred by the formula (used in IEC 60335-2-40), provided the release height was above around $0.6 \mathrm{~m}$ from the floor. It is noted that the formula used an assumption of fixed flammable volume-time and except for the general information that this was quantified using CFD, no details of their calculation procedures were given.

More recent analysis (Colbourne and Suen, 2016; 2018) found that the assumption of pure refrigerant emerging from the IDUE was far from valid. Whilst the exiting velocity was indeed "low" (relative to the discharge jet velocity) the unit exiting concentration $\left(C_{\text {exit }}\right)$ differed substantially, depending upon both the refrigerant release mass flow, orientation and position within the AC IDUE. The same was observed with other types of enclosures and $C_{\text {exit }}$ was found to be dependent upon the internal position of the jet, its orientation and the proximity of the jet to impingement surfaces. Even with a high release mass flow, such as $100 \mathrm{~g} \mathrm{~min}^{-1}$, the highest $C_{\text {exit }}$ was in the order of $5-10 \% \mathrm{R} 290$ by volume, due to mixing with air before emerging from the enclosure. Different IDUEs and enclosure geometries were shown to influence $C_{\text {exit }}$ and thus $C_{f l o o r}$. Additional experiments highlighted how internal geometries of the IDUE could be manipulated to reduce $C_{\text {floor }}$ and it is evident that RACHP-enclosure configuration can have a major impact on $C_{\text {floor }}$ and thus the ACL, assuming that LFL needs to be avoided at floor level. The present work has thus been carried out in order to establish possible formulations for estimating a more flexible ACL, based primarily on experimental observations.

\section{Methodology}

Tests were conducted to measure $C_{f l o o r}$ arising from releases from various RACHP units in a sealed room of $4.5 \mathrm{~m} \times 3.0 \mathrm{~m}$ floor area and $3.0 \mathrm{~m}$ high. Room air speed was checked (in absence of mechanical airflow) with an omnidirectional hot wire anemometer to confirm all readings were less than $0.02 \mathrm{~m} \mathrm{~s}^{-1}$ before starting the 
measurements. Multiple gas sensors (pellistors with a range of 0-5\% R290 and infra-red type with a range 0$100 \%$ R290; accuracy $\pm 3 \%$ of the reading) were positioned-at the floor level and at various height increments (with a tape measure, assumed to be accurate to within $\pm 1 \%$ ) in the centre of the room, in a formation appropriate for the test objective and RACHP equipment used. All sensors were subject to regular re-calibration for R290.

Leak hole sizes and associated mass flows have been discussed in Colbourne et al. (2020b) where over 95\% of the largest "uninterfered" leak holes (i.e., without intervention of a service technician) were found to be less than $0.5 \mathrm{~mm}^{2}$ which correspond to a release mass flow of R290 vapour of around $30 \mathrm{~g} \mathrm{~min}^{-1}$ to $60 \mathrm{~g} \mathrm{~min}$ ${ }^{1}$, depending on the system pressures. Since leak hole size and corresponding release mass flow dictate all subsequent parameters associated with avoiding $C_{\text {floor }} \geq \mathrm{LFL}$, release mass flows in this order and greater were used to examine the effect of the variables associated with the RACHP enclosures.

Only R290 has been used in this study, since it is by far the most widely used A3 refrigerant, although additional work is ongoing to extrapolate the findings to other flammable refrigerants. Refrigerant was released through a capillary tube or fixed orifice with diameters from 0.5 to $2.0 \mathrm{~mm}$, selected to ensure choked flow delivered at a fixed velocity for the selected release mass flows; the flow was controlled by a mass flow controller, with an accuracy of $\pm 1 \%$ of the reading. Measurements were carried out on wall AC, window AC and floor AC units, as well as a "variable enclosure" (VE) that could be modified to simulate the constructional characteristics of most common commercial refrigeration (CR) and AC IDUEs. The results are analysed to identify common characteristic behaviour for developing new ACL formulations.

Measurements were made when the room temperature was at $25^{\circ} \mathrm{C} \pm 2 \mathrm{~K}$ and under the test conditions the density of R290 ranges between 1.85 and $1.82 \mathrm{~kg} \mathrm{~m}^{-3}$. Preliminary evaluations of the effect of room temperature on the mixing rate, expressed as a variation in $C_{\text {floor }}$, showed negligible influence, as the relative densities of air and R290 remained fairly constant within this temperature range.

Figure 1 shows some common RACHP equipment enclosures and several of these have been examined directly or in principle in this study. The key differences arise from the relative position of their openings (indicated with dashed line boxes) and that along with the position of the release itself affect the dispersion of any leaked refrigerant in the surrounding space. 


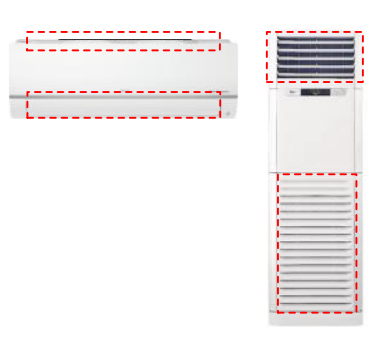

(i) Wall-type

(ii) Cabinet-type

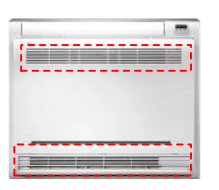

(iii) Floor-type

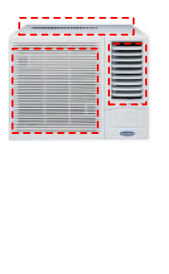

(iv) Window-type

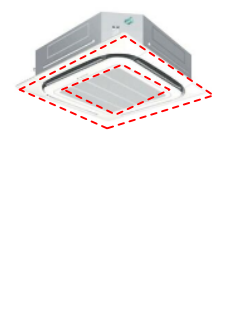

(v) Ceiling cassette

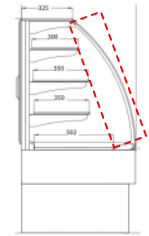

(vi) Serve-over

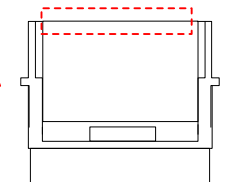

(vii) Gondola

cabinet

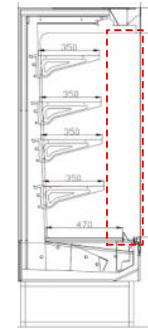

(viii) Multideck cabinet

Figure 1 Common RACHP enclosures showing opening positions (dashed line boxes)

\subsection{Wall-type AC units}

The wall type IDUEs were mounted at between $0.5 \mathrm{~m}$ to $1.8 \mathrm{~m}$. Releases of R290 were via a capillary tube at the far-right end bottom within the IDUE, behind the louver; this particular release position had been found to yield the highest $C_{\text {floor }}$ in the test room (Colbourne and Suen, 2018). The IDUE was located at the narrower end of the room, with the intention of giving a higher $C_{f l o o r}$, compared to the IDUE being against the wider end of the room. Release of R290 was initiated and then terminated at the time when the floor concentration at the centre of the room reached LFL $\left(38 \mathrm{~g} \mathrm{~m}^{-3}\right)$. In this way, it is possible to determine the maximum releasable quantity before a flammable volume is formed across the room floor. Figure 2 presents the local concentration at incremental heights (i.e. height-concentration profiles, $\mathrm{HCP}$ ) in the centre of the room at the time when $C_{\text {floor }}$ reached LFL, for two different IDUE heights $(0.5$ and $1.5 \mathrm{~m})$ and different release mass flow $\left(60 \mathrm{~g} \mathrm{~min}^{-1}\right.$ and $\left.150 \mathrm{~g} \mathrm{~min}^{-1}\right)$. It can be observed that the concentration arising from releases at a lower elevation are less sensitive to release mass flow and releases at a higher elevation tend to form distinct near-homogenous layer-volumes.

Figure 3 presents the released mass when $C_{\text {floor }}=$ LFL for various IDUE heights and release mass flows. The data shows that the higher the IDUE and with a lower mass flow, more refrigerant can be released before reaching LFL. Also included in Figure 3 are three data-points showing the maximum charge according to the ACL formula in IEC 60335-2-40, based on the same IDUE heights and at a mass flow corresponding to the total charge released over four minutes. There is a noticeable difference between what is prescribed by the formula and observed from measurements - taking all other parameters to be essentially identical - with the latter being two to five times higher, suggesting that the development of the formula may have neglected some important factors, such as opening dimensions and release jet orientation and velocity. A direct comparison cannot be easily made, since for IEC 60335-2-40 the releases were from a diffuser. The work of Colbourne and Suen (2018) shows that maximum $C_{\text {floor }}$ is higher by at a factor of two with the diffuser, for which the $C_{\text {floor }}$ rise almost instantaneously a few moments after the beginning of the release and vary wildly depending upon the floor location relative to the release source. 


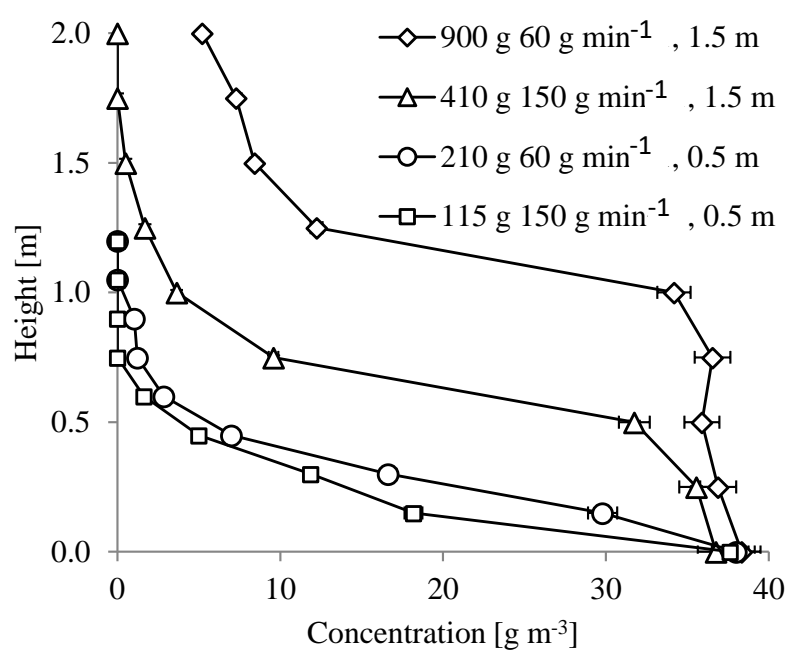

Figure 2 HCPs of 2290 release with IDUE at different heights and with various release mass and mass flows

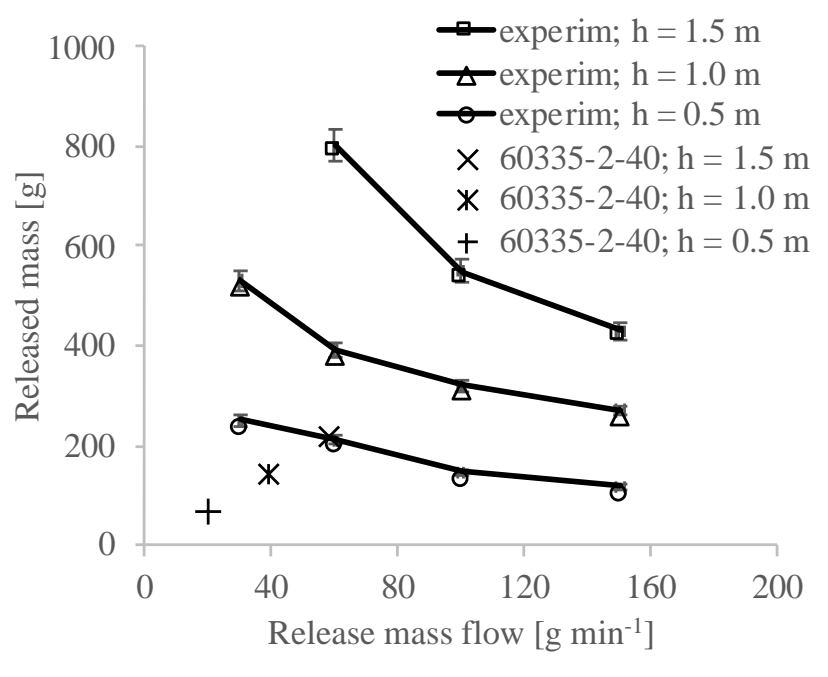

Figure 3 R290 released mass to reach LFL at room floor centre with IDUE at different heights and release mass flows

\subsection{Window AC units}

Measurements were also carried out with a window type AC, where the entire unit was placed within the test room (as opposed to partially through a wall) with its base at a height of $1.0 \mathrm{~m}$. Depending upon the release position within the enclosure and its orientation, different proportions of the released mass will exit from various openings. Therefore, to eliminate this variability and veer towards the most pessimistic outcome, for certain measurements all sides except the front were sealed (Figure 4), thereby directing the released refrigerant to exit from the front of the unit.

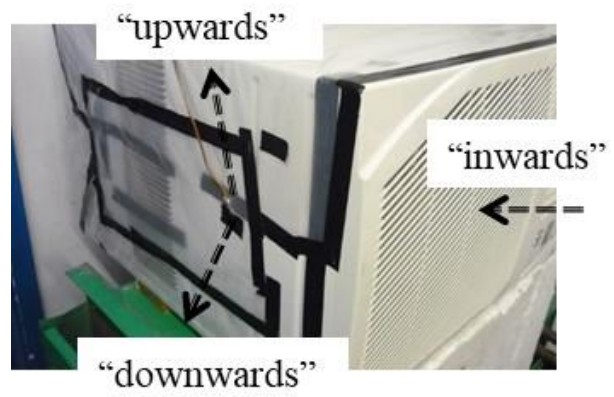

Figure 4 Window AC with sealing to top and all sides, except front grille, with arrows indicating the release directions inside the enclosure

Figure 5 presents the HCPs corresponding to a release of $410 \mathrm{~g}$ to $480 \mathrm{~g}$ at $60 \mathrm{~g} \mathrm{~min}^{-1}$, where $C_{\text {floor }}$ reaches LFL for the most severe cases. Situations that led to the highest floor concentrations were when the release occurred from the left-hand return bends (LHRB) between the inner panel and enclosure side panel, regardless of the release directions. For the case where the rear end was also open ("open"), the floor 
concentration was substantially lower. A release in the middle of the coil and directed inwards into the unit ("mid coil") was found to result in a low $C_{\text {floor }}$ too, despite larger quantities of R290 being released. This reflects the importance of the location and orientation of the release within the enclosure. Since the side and rear parts of the enclosure would ordinarily be in the open air, it is likely that room concentrations would be lower in a "real" situation.

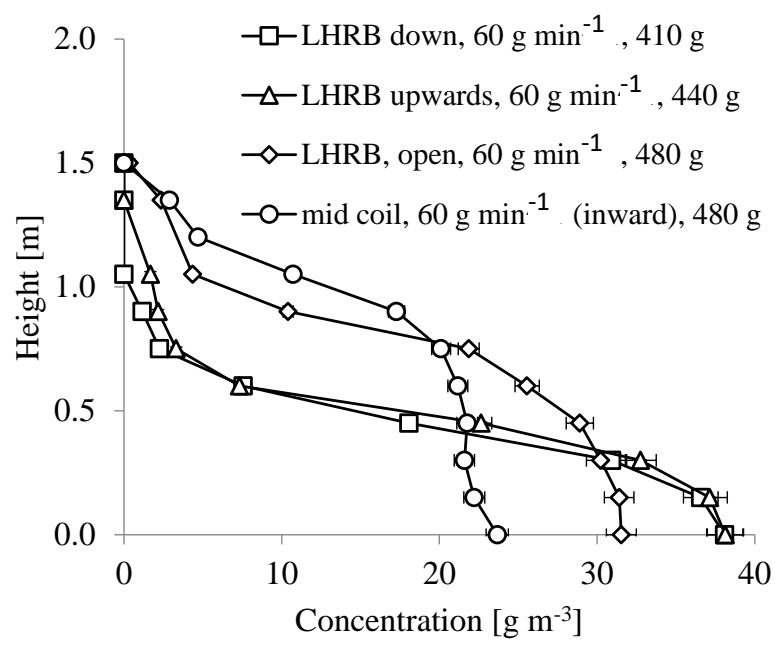

Figure 5 HCPs at the end of the release for window unit

It is expected that a window AC unit will require a relatively large release of refrigerant for the local floor area to reach or exceed LFL. This is due to most of the release exiting the enclosure from the condenser-side openings. An important question is how much of the release actually flows into the conditioned space - this could have a major implication on ACL.

\subsection{Floor AC units}

Several tests were conducted for a floor type split AC IDUE that was first placed at $0.15 \mathrm{~m}$ above the floor. A fixed mass of $150 \mathrm{~g}$ of R290 was released, rather than terminating when $C_{f l o o r}$ reached LFL, and the release mass flow was set respectively at 20,40 and $60 \mathrm{~g} \mathrm{~min}^{-1}$.

There were two main potential leak points: one close to the inner base where there is usually a connector to the piping at about $0.2 \mathrm{~m}$ above the internal base and a second at the heat exchanger (HX) right-hand return bends (RHRB), at about $0.5 \mathrm{~m}$ above the base, on either end of the evaporator. Releases from the connecting joint were made beneath the pipe insulation, which usually is to the detriment of good mixing as it tends to muffle the release.

The HCPs for the release when the IDUE was at $0.15 \mathrm{~m}$ above the floor are presented in Figure 6. Under certain conditions, highest $C_{\text {floor }}$ was found to easily reach or exceed LFL. Surprisingly, although the release from the return bends occurred from a higher elevation than the connector, the latter has higher $C_{f l o o r}$. This 
is likely due to the much smaller internal volume in the proximity of the side panel, thus entraining substantially less fresh air. In both cases, the mass flow does not seem to affect the maximum $C_{\text {floor }}$, probably due to the improved 'pre-mixing' within the enclosure on account of the jet's higher exit momentum.

Further tests were performed when the IDUE was raised to $1.0 \mathrm{~m}$ height, with a greater released mass, $400 \mathrm{~g}$ at both 60 and $90 \mathrm{~g} \mathrm{~min}^{-1}$, also presented in Figure 6. For the connector, at two release mass flows, the maximum $C_{f l o o r}$ are virtually the same; a similar observation is apparent with the releases from the RHRBs. When compared to the results at $0.15 \mathrm{~m}$ unit height, it is evident that when the IDUE is close to the floor level, the $C_{\text {floor }}$ is likely to exceed the LFL, suggesting that other protective measures would be necessary.
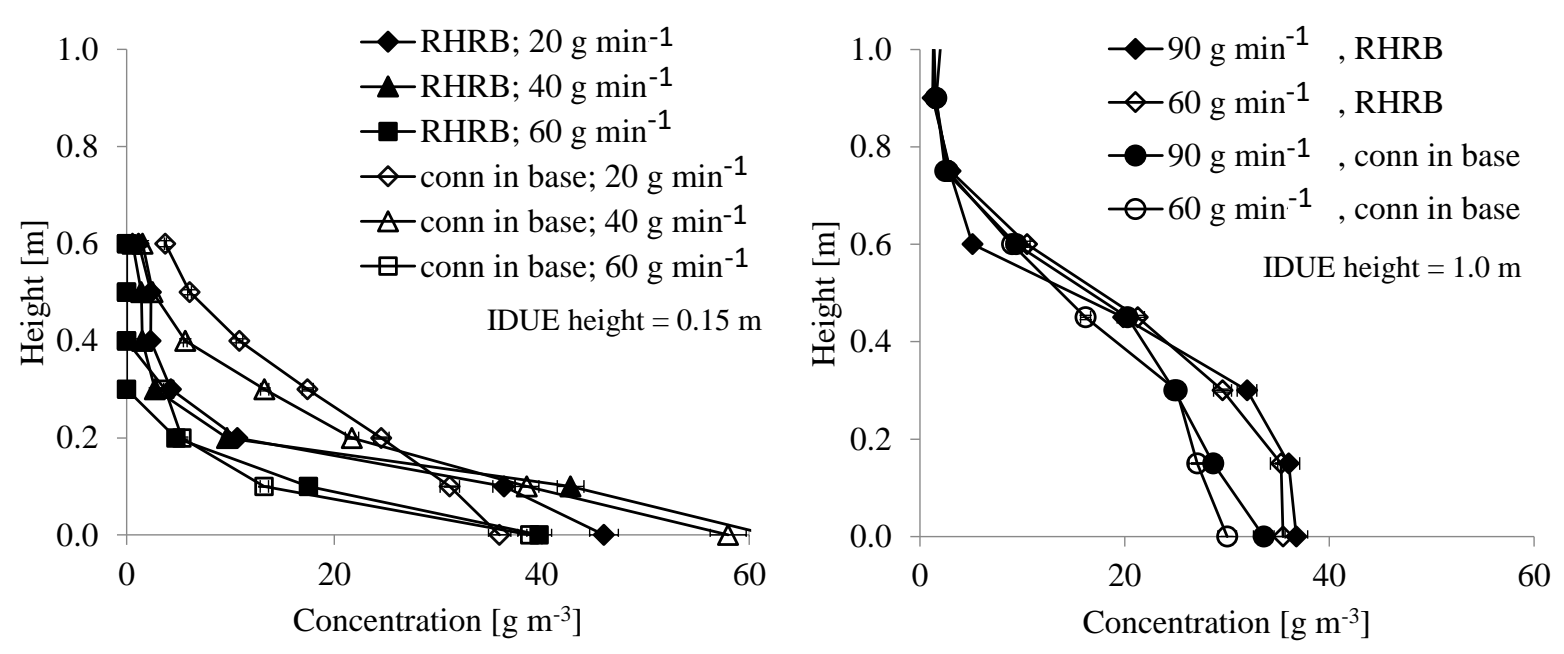

Figure 6 HCPs for $0.15 \mathrm{~kg}$ releases from connector and RHRB when IDUE at $0.15 \mathrm{~m}$ above floor for mass flow of 20, 40 and $60 \mathrm{~g} \mathrm{~min}^{-1}$, and HCPs for releases of $400 \mathrm{~g}$ when the IDUE is at $1.0 \mathrm{~m}$

\subsection{Variable enclosure (VE)}

Similar measurements were carried out with a variable enclosure (VE); the framed construction (Figure 7) enabled internal height and width to be varied as well as the number, location and dimensions of the front openings. The objective was to be able to mimic some of the basic constructional characteristics of RACHP enclosures, including cabinet type AC units, multi-deck cabinets, etc., as shown in Figure 1.

Concentrations were measured both within the enclosure and room. In addition, sensors were positioned (just on the inside of the VE envelope) to capture $C_{\text {exit }}$ at various horizontal and vertical spatial intervals along the front opening as shown in Figure 7. The enclosure has one single full-width opening $1.8 \mathrm{~m}$ by $1.3 \mathrm{~m}$ high. Other opening heights $\left(h_{o}\right)$ ranging from $0.1 \mathrm{~m}$ upwards were also examined, whereas all other sides were sealed. Releases were made from different positions within the enclosure, generally at the centre of the rear wall at three different heights and also at the left rear side. In certain cases, two openings (ranging from $0.1 \mathrm{~m} \times 1.8 \mathrm{~m}$ to $0.37 \mathrm{~m} \times 1.8 \mathrm{~m}$ ) were used; one at the lower part of the VE front and a second at the upper 
part. In addition, some tests employed a small axial fan at the base of the VE to mimic evaporator airflow internally. A so-called "impinger-diffuser" (Figure 7) was designed and used to mimic the practical situation where a high velocity jet impinges on a nearby surface and thus reduces the momentum of the refrigerant jet.

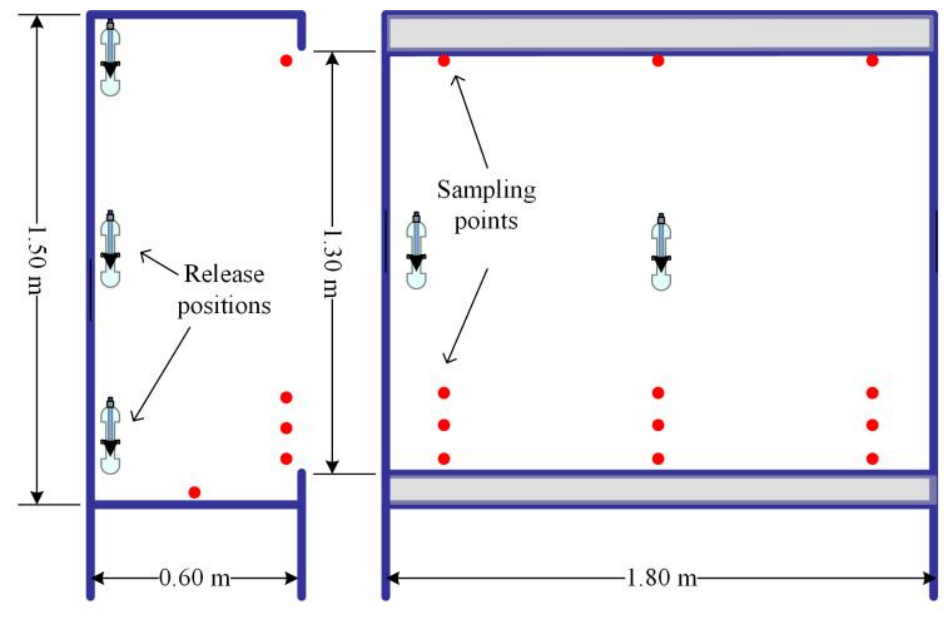

VE side view

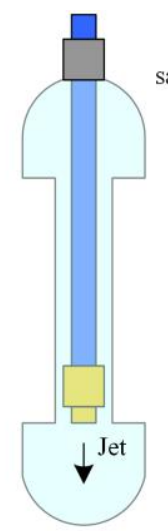

Impinger-diffuser

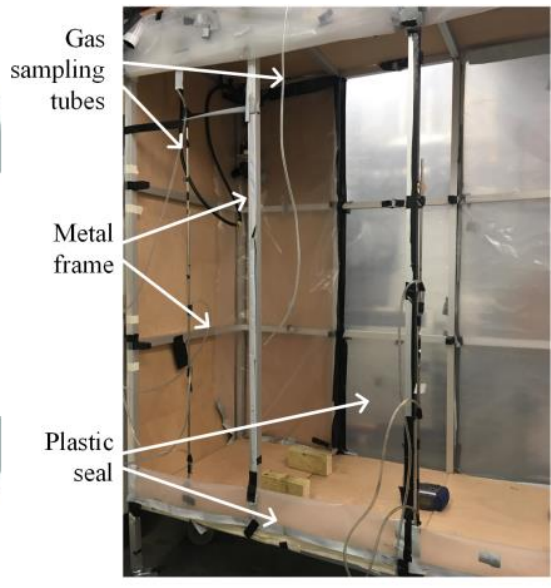

Photograph of VE

Figure 7 Test arrangement for variable enclosure, and locations of sampling and release points

Examples of developing average $C_{\text {floor }}\left(\bar{C}_{\text {floor }}\right)$ over time arising from a $300 \mathrm{~g}$ and $30 \mathrm{~g} \mathrm{~min}^{-1}$ release under different VE configurations and release positions are shown in Figure 8. The results are shown for the release phase and partially for the "natural" decay phase, i.e., prior to any ventilation being initiated. Position and size of the opening(s), and the location of the release are found to have a significant impact on $\bar{C}_{f l o o r}$. For instance, with a high release point and large opening (Case a), the highest $\bar{C}_{\text {floor }}$ only reaches about $15 \mathrm{~g} \mathrm{~m}^{-3}$, whereas a low release position of any opening size (Case b and d) or a low opening irrespective of the release location (Case c and d) can give $\bar{C}_{\text {floor }}$ as high as $25 \mathrm{~g} \mathrm{~m}^{-3}$. In the case of a double opening construction (Case e), $\bar{C}_{\text {floor }}$ is much lower than Case c and closer to that of Case a. Important aspects for low $\bar{C}_{\text {floor }}$ appear to be greater distance between release point and VE base for entrainment to occur, and suitable openings for air movement; for Cases b, $\mathrm{c}$ and d, the releases probably entrain least fresh air, thus leading to minimal internal mixing. 


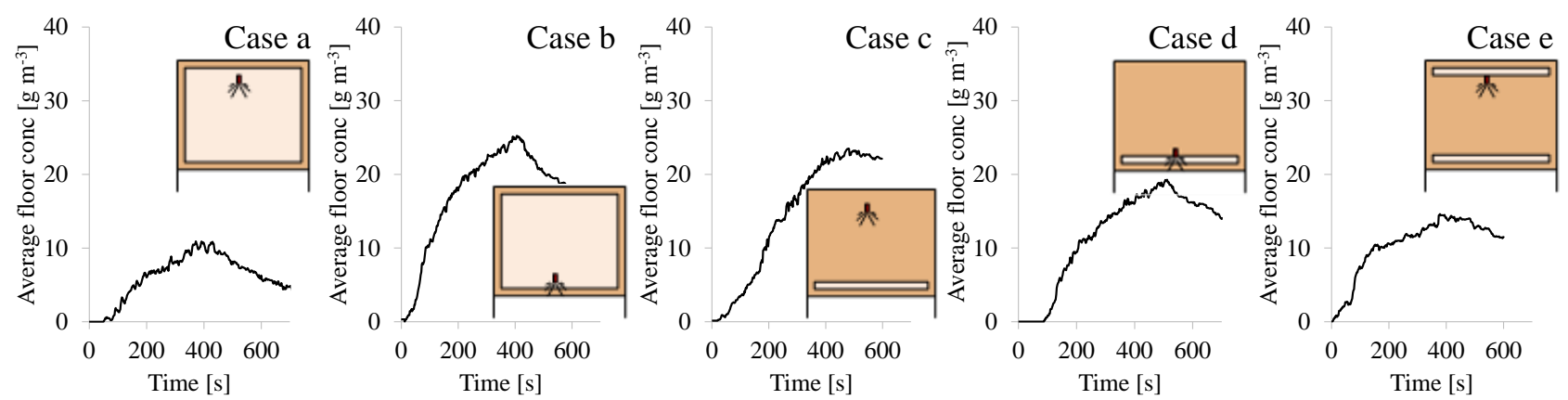

Figure 8 Variations of average floor concentration over time for different size and position of opening $(s)$ and location of release points; all VE diagrams are front view projections

Across the initial set of 30 tests, the results (time-averaged over $60 \mathrm{~s}$ ) show generally that a lower value of VE maximum $C_{\text {exit }}$ tends to give a lower $\bar{C}_{\text {floor }}$ (Figure 9). Considering the breadth of variables including VE opening dimensions and release locations, and also the cases with internal airflow (i.e., within the VE), there is a clear correlation between $\bar{C}_{\text {floor }}$ and maximum $C_{\text {exit }}$. This suggests that enclosures could be designed to give a lower $\bar{C}_{\text {floor }}$ by achieving a lower $C_{\text {exit }}$.

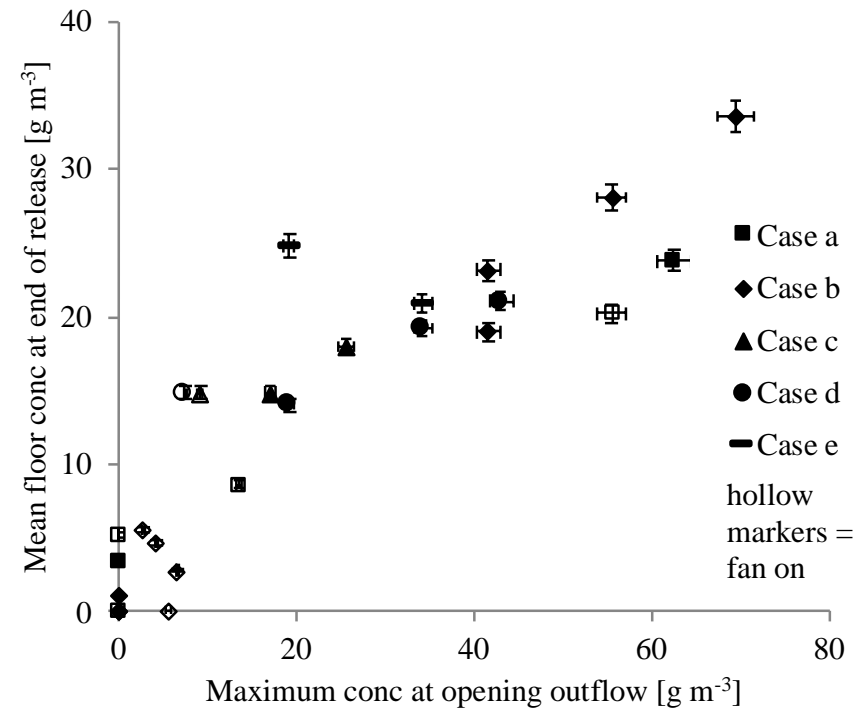

Figure $9 \bar{C}_{\text {floor }}$ and maximum $C_{\text {exit }}$ for different VE configurations; the hollow markers indicate the cases where the internal fan was on. Where measured concentrations are indicated as about $0 \mathrm{~g} \mathrm{~m}^{-3}$, this occurs due to the resolution of the sensors being unable to differentiate these low values

Figure 10 provides some sample HCPs for the centre of the room and also at the enclosure opening, using three different mass flows and released masses. At the opening, there is a slight increase in local $C_{\text {exit }}$ as the position decreases in height towards about $0.5 \mathrm{~m}$ above the internal VE base. These values consistently match the concentration within the room. From this level downwards, the room concentrations show a small increase when approaching the floor level. Towards the base of VE, $C_{\text {exit }}$ tends to depart from the room concentration where a much greater increase in local $C_{\text {exit }}$ occurs. As would be expected, a higher mass flow results in a higher $C_{\text {exit }}$ that translates into a higher $C_{f l o o r}$. 


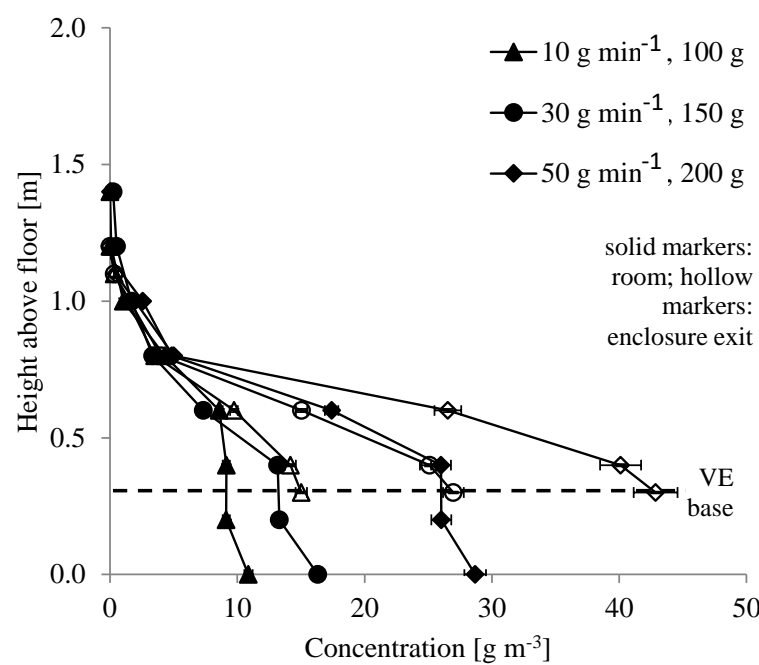

Figure 10 HCPs for a selected VE (Case a) with three different release mass flows; release height $1.05 \mathrm{~m}$ above floor; $V E$ width $=0.6 \mathrm{~m}$

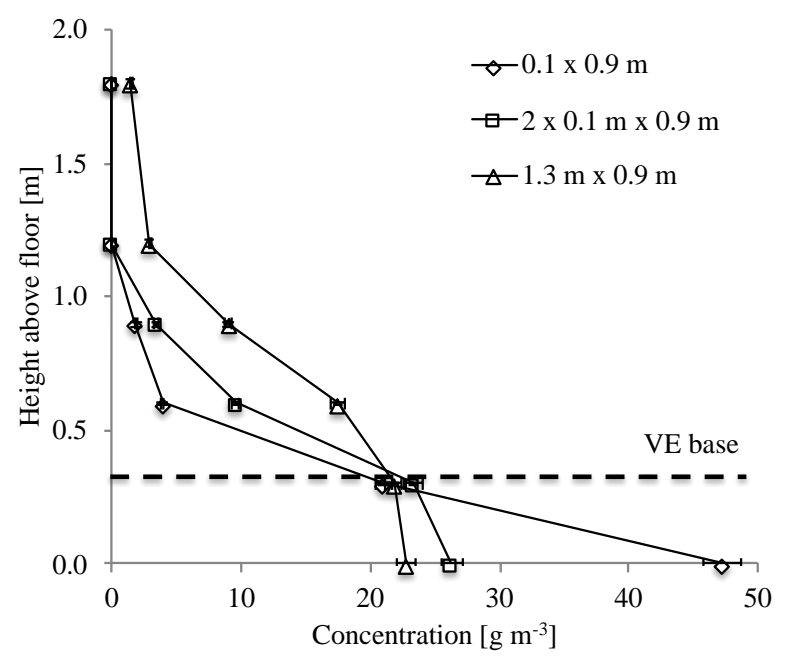

Figure $11 \mathrm{HCP}$ in room centre for release from VE with different opening sizes; release of $300 \mathrm{~g}$ at $30 \mathrm{~g}$ $\mathrm{min}^{-1}$ at height $1.8 \mathrm{~m}$ above floor, VE width of $0.9 \mathrm{~m}$

Figure 11 shows HCPs for three different VE opening arrangements. Where there is a single thin opening $(0.1 \mathrm{~m} \times 0.9 \mathrm{~m})$ at the VE base, the profile indicates relatively a lot more refrigerant present close to the floor and little above the unit base height. However, where there is one large opening $(1.3 \mathrm{~m} \times 0.9 \mathrm{~m})$ the HCP is steeper. Importantly, despite the situation with two thin openings $(2 \times 0.1 \mathrm{~m} \times 0.9 \mathrm{~m})$, the HCP is rather similar to that with the single large opening. This infers that with the second opening the mixture is able to flow out more easily, thus drawing in fresh air from the top and mimicking the large opening. For the VE, it appears that conditions which lead to a higher $C_{\text {exit }}$ also led to higher $C_{f l o o r}$.

\subsection{Main observations}

Key observations from the tests are that at the point when $C_{\text {floor }}$ approaches LFL or the release has terminated, the HCP in the room differs according to the position of the release inside the IDUE or VE, the height of the unit, the mass flow and the mass of the release. In addition, the opening size, number and position, as well as the internal configuration and volume of the enclosure also play a role in influencing the HCPs. In general, the lower the $C_{\text {exit }}$, the lower the $C_{\text {floor }}$, implying relatively more mass could be released before reaching a certain $C_{\text {floor }}$. A lower and smaller opening would lead to a higher $C_{f l o o r}$ and conversely a larger opening gives smaller $C_{f l o o r}$. Two small openings result in $C_{f l o o r}$ similar to one large opening. These observations will help form the approach for determining ACL.

In this study we are proposing a simple expression, equation (1), to estimate the ACL $\left(m_{A C L}\right)$ which consists of four parameters, based on the following. Naturally the refrigerant (hence its $L F L$ ) and the size of the room are expected to play a role. The other two parameters include a representative height $\left(h^{*}\right)$ to account for the above factors and an adjustment factor, $F_{L F L}$, to additionally account for mass flow of the release. 


$$
\boldsymbol{m}_{A C L}=L F L \times A \times h^{*} \times F_{L F L}
$$

where $L F L=$ lower flammability limit $\left[\mathrm{kg} \mathrm{m}^{-3}\right], A=$ room area $\left[\mathrm{m}^{2}\right], h^{*}=$ representative height of the refrigerant layer-volume inside the room, expressed in terms of enclosure and opening parameters $[\mathrm{m}]$, and $F_{L F L}$ is an adjustment factor applied to the $L F L[-]$.

Conversely for a given charge $\left(m_{C}\right)$, the minimum room area $\left(A_{\min }\right)$ to avoid LFL at the floor can be determined from equation (2).

$$
A_{\min }=\frac{m_{C}}{F_{L F L} \times L F L \times h^{*}}
$$

where $m_{C}=$ refrigerant charge $[\mathrm{kg}]$.

However, at this stage it is considered the internal configuration of the enclosure is too complicated to be included in this study. Based on the observations, a general rule was established to determine the suitable values of $h^{*}$ and $F_{L F L}$.

\subsection{Approximating $\boldsymbol{h}^{*}$}

For the IDUE (wall-type AC unit), Figure 12 presents the variations of $C_{f l o o r}$ and refrigerant layer-volume height with the released mass, for respectively three release mass flows of 30, 60 and $100 \mathrm{~g} \mathrm{~min}^{-1}$. During the release, there is a gradual increase of refrigerant layer-volume height, until a maximum "steady" value is reached. Further increase in the released mass does not appear to affect the height much, though the R290 concentration within the layer-volume continues to rise.

When comparing the three mass flows, a higher flow is found to result in relatively a higher $C_{\text {exit }}$ and $C_{\text {floor }}$ as well as a shorter time taken to reach the maximum height; the corresponding $C_{\text {exit }}$ values are respectively 70,110 and $150 \mathrm{~g} \mathrm{~m}^{-3}$. Notably, they all have almost the same maximum layer height close to IDUE base (the dashed line). This is similar to the observation made by Baines and Turner (1969) and the latter work of Cleaver et al. (1994) regarding the plume-filling box hypothesis. This supports the use of the approximate base height of the enclosure relative to the floor $\left(h_{\text {base }}\right)$ as $h^{*}$ for the IDUE. 

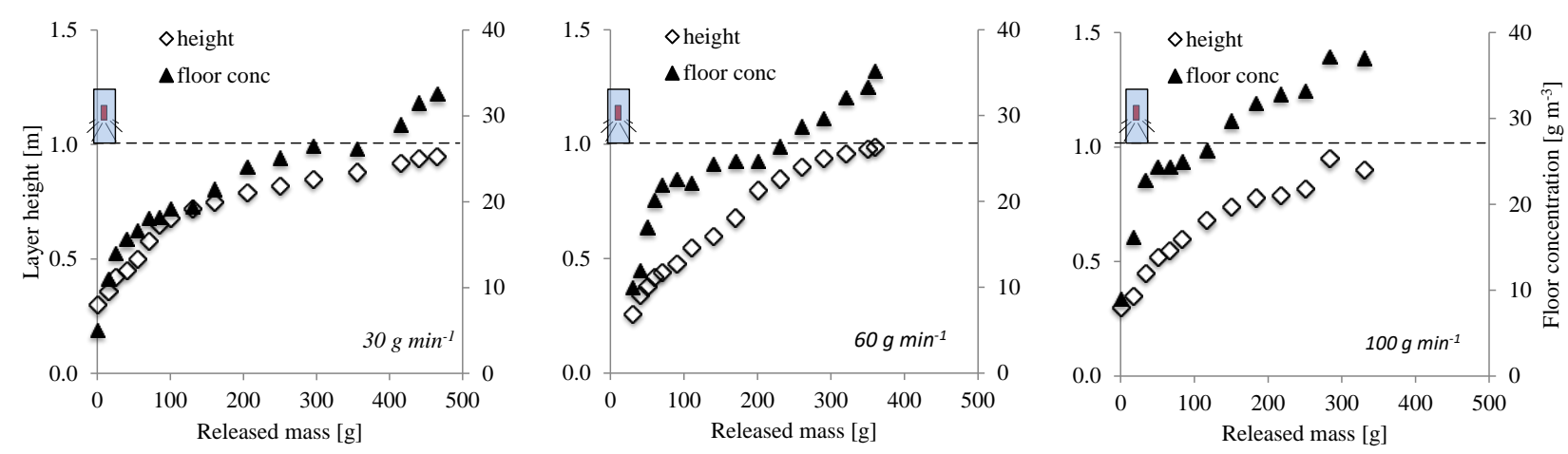

Figure 12 Change in layer-volume height and $C_{\text {floor }}$ over time for different IDUE release mass flows. The uncertainty of the layer-volume-height is $\pm 0.10 \mathrm{~m}$, concentration $\pm 3 \%$

The other relevant geometric parameters are also defined as in Figure 13, e.g. $h_{\text {lower, bot }}$ refers to the height of the bottom edge of the lower window relative to the floor and $d_{v e}$ is the depth of the enclosure. For a given enclosure width $\left(w_{i d u e}\right.$ or $\left.w_{V E}\right)$, the size of the opening is termed $h_{o}$, which is taken as e.g., $h_{o}=$ $h_{\text {lower,top }}-h_{\text {lower, bot }}$.
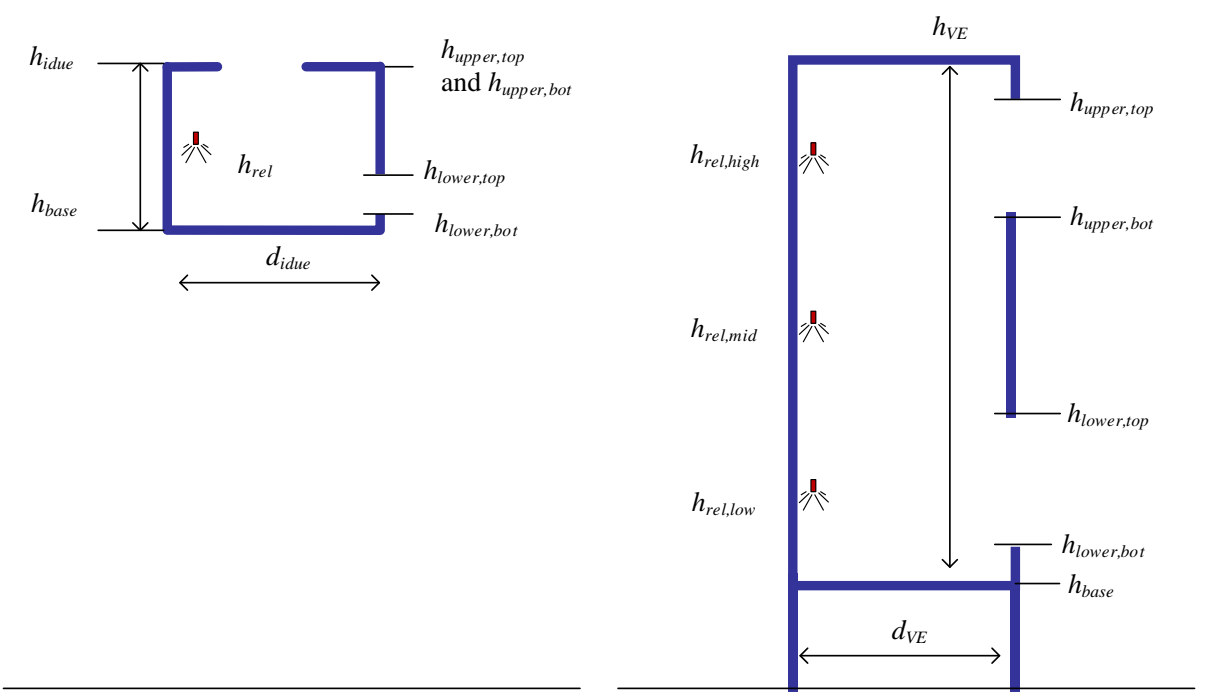

Figure 13 Defining the associated heights of VE and IDUE; side view projections

Figure 14 presents some sample behaviour for various VE configurations, where the release position/height (represented by the "spray" icon) is changed, and the mass flow is fixed at $30 \mathrm{~g} \mathrm{~min}^{-1}$. Six cases are presented, based on the set up in Figure 8 and two different opening sizes $\left(h_{o}\right)$ for case c are used. In most cases the height of the layer is again seen to asymptote after an initial period. With a low release point (case $\mathrm{d}$ and b), the layer-volume height acquires a value very close to $h_{\text {lower,bot }}$ and appears to be not too sensitive to the size of the opening and as expected, there is a rapid increase in the $C_{\text {floor }}$ with the time/released mass.

On the other hand, it can be seen in general that a higher release point would result in an increase in the layer-volume height, but correspondingly with a lower $C_{f l o o r}$, and in some cases $L F L$ is never reached. For 
certain cases (two cases $\mathrm{c}$ and case a), all with the opening base position fixed $\left(h_{\text {lower, } b o t}=0.4 \mathrm{~m}\right.$ ) and a high release point, the final layer-volume height is found to rise initially with increasing opening size ( $h_{\text {lower,top }}$ is increased from $0.5 \mathrm{~m}$ to $1.1 \mathrm{~m}$ ), but it then becomes insensitive to further increase of the opening size. It also seems with two openings, an upper and a lower one (case e), it behaves rather similar to that of one big opening (case a), when they share the same $h_{\text {lower, bot }}$.
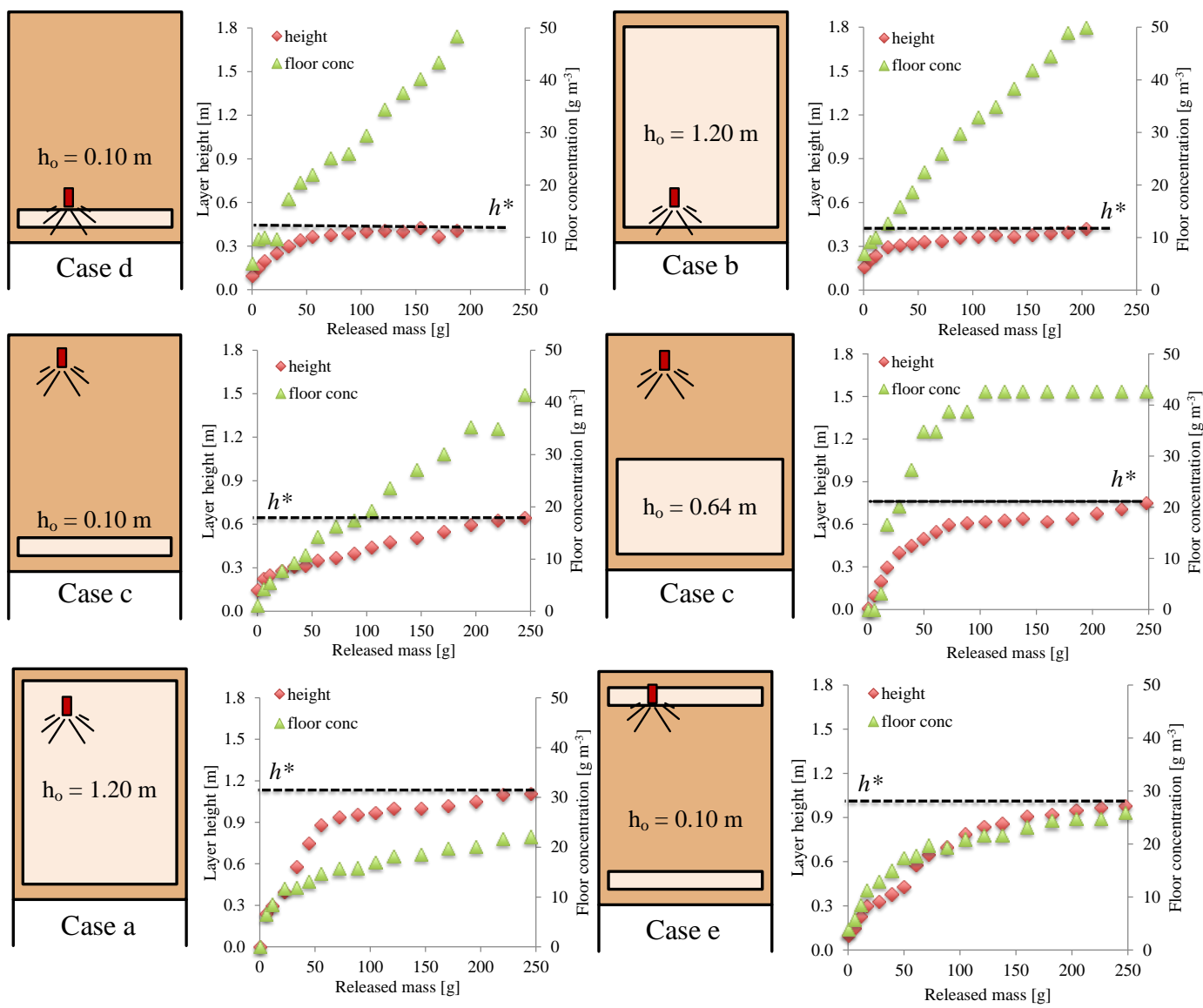

Figure 14 Variations of layer-volume height and floor concentration with released mass for different VE and release configurations, all with a release of $300 \mathrm{~g}$ and mass flow of $30 \mathrm{~g} \mathrm{~min} \mathrm{~m}^{-1}$. Uncertainty of the layer height is $\pm 0.10 \mathrm{~m}$, concentration $\pm 3 \%$. Diagrams of VEs are front-view projections.

When filtering the data, "low" and "high" for release height $\left(h_{r e l}\right)$ are $<0.5 \mathrm{~m}$ and $\geq 0.5 \mathrm{~m}$ relative to the floor, respectively, "small" and "large" opening sizes are those with $h_{o}<0.5 \mathrm{~m}$ and $\geq 0.5 \mathrm{~m}$ high, respectively, and a "low" opening position is one with $h_{\text {lower, bot }}<0.5 \mathrm{~m}$. An analysis was made across many tens of experiments, which used a variety of VE and release configurations. Observations suggest that a general rule can be established to approximate $h^{*}$.

As long as the release point is at the low position (i.e. for cases $\mathrm{d}$ and $\mathrm{b}$ ), the results suggest that $h^{*}$ is always just approximating $h_{\text {lower, bot }}$, as expressed by equation (3), regardless of whether the opening size is large or small, thus, 


$$
h^{*} \cong h_{\text {lower, bot }}
$$

When the release position is high and $h_{\text {lower,bot }}$ is close to the VE base, as in the cases a, c and e the observations suggest equation (4) could be used to approximate $h^{*}$. The coefficients $\alpha$ and $\beta$ describe the trend and needs to be derived from fitting experimental data to the equation. For the applicable cases in Figure $14, \alpha=1.5$ and $\beta=0.8$.

$$
h^{*}=\alpha\left(1-e^{-\beta \times h_{\text {lower,top }}}\right)
$$

It is noted that where there are two small openings (case e), one near the VE top and the other close to the VE base, it could be treated as equivalent to having a single large opening as in case a. The same expression could be used but with $h_{\text {lower,top }}$ replaced by $h_{\text {upper,top }}$ in the equation.

Whilst equation (4) was found to provide good approximation, it relies upon the availability of experimental data. As an alternative, equation (5) has been found to be able to estimate $h^{*}$ to within $\pm 15 \%$ of the experimental $h^{*}$.

$$
h^{*}=\frac{1}{2}\left(h_{\text {lower, bot }}+h_{\text {upper,top }}\right)
$$

Note that if the release height is below that of the upper lip, it can be substituted for the purpose of applying equation (4) or equation (5), i.e., $h_{\text {rel }}$ replaces $h_{\text {upper,top }}$.

One final case is where the release position is substantially lower than $h_{\text {lower,bot }}$ (referred as the "bucket case"; examples include ice-cream freezers or well-type cabinets), the data [not included here] supports the use of equation (3).

When insufficient characteristics of the RACHP enclosure are known, it can default to $h^{*}=h_{\text {base }}$, which provides a more conservative estimation of ACL.

\subsection{Determination of $\boldsymbol{F}_{L F L}$}

For a given floor area, simply using the layer height $h^{*}$ and $L F L$ in equation (1) could lead to an overestimation of the charge limit due to significant variations in HCPs caused by different enclosure characteristics and release conditions. Therefore, an adjustment factor $F_{L F L}(<1)$ is introduced in the equation, to effectively reduce the flammable layer-volume below the $h^{*}$ where the mixture collects. For a given IDUE or VE and release conditions, the HCPs across the room are integrated to essentially provide an estimation of refrigerant mass within the layer volume at the time when the $C_{f l o o r}$ reaches $L F L$, and to 
transpose equation (1) to give the corresponding $F_{L F L}$ value, as expressed in equation (6). Comparing the two HCPs in Figure 6, one could tell that the one with a IDUE height of $0.15 \mathrm{~m}$ has a smaller refrigerant mass within the layer-volume than the one at $1.0 \mathrm{~m}$ height, when the $C_{\text {floor }}$ reaches $L F L$, and accordingly it would have relatively a smaller $F_{L F L}$.

$$
F_{L F L}=\frac{\sum_{i=1}^{h^{*}} C_{i}}{L F L}
$$

where $C_{i}$ is the concentration with respect to $h$.

Measurements were made for various IDUEs and VEs across a wide range of arrangements and conditions allowed the corresponding $F_{L F L}$ to be determined. Following the previous observation that the HCP is strongly dependent upon $C_{\text {exit }}$, it is proposed to correlate the $F_{L F L}$ data, as presented in Figure 15, with the highest concentration exiting the enclosure into the room, $C_{\text {exit }}$. An empirical correlation between $F_{L F L}$ and $C_{\text {exit }}$ has been established by curve fitting, as expressed in equations (7) and (8), respectively for IDUEs and VEs. Note that the curves are fitted to the lower boundary of the $F_{L F L}$ data points so as to generate a correlation that would yield a more stringent outcome for the charge limit. It can be seen that in general the $F_{L F L}$ decreases with increasing $C_{\text {exit }}$, implying that a higher $C_{\text {exit }}$ would lead to a lower ACL. However, the $F_{L F L}$ becomes relatively insensitive to $C_{\text {exit }}$ as the latter keeps increasing. $C_{\text {exit }}$ in equation (7) and (8) can be, (i) calculated, (ii) determined by measurement or (iii) set as the density of the pure refrigerant vapour at atmospheric pressure and room temperature, i.e. $C_{\text {exit }}=1850 \mathrm{~g} \mathrm{~m}^{-3}$ for pure R290, although this will lead to the most conservative value of $F_{L F L}$.

$$
\begin{gathered}
F_{L F L, I D U E}=4 \times C_{\text {exit }}^{-2 / 5} \\
F_{L F L, V E}=2 \times C_{\text {exit }}^{-1 / 3}
\end{gathered}
$$

Relative to IDUEs, for the same $C_{\text {exit }}$, VE type constructions have lower $F_{L F L}$ values because they tend to inhibit mixing of the released refrigerant, due to primarily the "channelling" effect that an open front enclosure is expected to have, when the descending refrigerant plume is bounded by the enclosure walls on all other sides. 


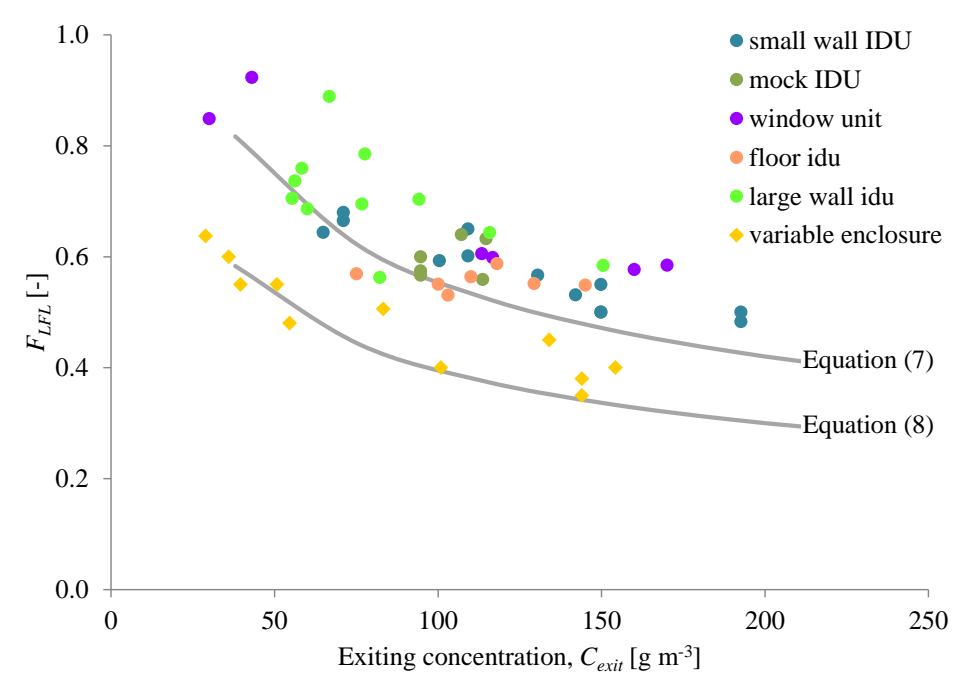

Figure $15 F_{L F L}$ for various IDUEs and VE, vs $C_{\text {exit }}$

\section{Sample ACL results}

Some IDUEs in Figure 1 are selected to illustrate the determination of the ACL using the proposed methodology and the results are presented in Table 1. The charge limits as prescribed in EN 378: 2016 for refrigeration cabinets, and IEC 60335-2-40: 2015 for air-conditioners and 60335-2-89: 2019 for commercial cabinets are also included.

In all cases, the room area is fixed $25 \mathrm{~m}^{2}$. For the refrigeration cabinets (Figure 1, vi, vii and viii), whilst the condensing unit is usually at the lowest position (on the floor, beneath the cabinet) it has been assumed that leaks only occur within the refrigerated enclosure; for them, the ACL remains the same since the standards (EN 378 and 60335-2-89) do not account for opening or unit height. For the EN378, the ACL remains the same for all cases as the calculation only relies upon space volume and LFL.

Based on the proposed formulations, the $m_{A C L}$ was found to be generally up to double or triple ACL as prescribed by the current standards. However, one case was seen to return a lower value due to its low $F_{L F L}$ value, suggesting that this could create a potentially higher risk situation if one used the quantities as specified in the current standards. It is also noted that the range of $F_{L F L}$ experienced is relatively small, suggesting that for most cases an average number could be used to approximate the $F_{L F L}$. On the other hand, a large range of $h^{*}$ values were encountered, depending upon the application. 
Table 1: Inputs parameters and allowable charge limits

\begin{tabular}{|c|c|c|c|c|c|c|c|c|c|c|}
\hline unit type & $h_{\text {base }}$ & $h_{\text {lower,bot }}$ & $h_{\text {lower,top }}$ & $h_{r e l}$ & $h^{*}$ & $\begin{array}{c}F_{L F L} \\
\text { From eqn. (7) } \\
\text { or (8) }\end{array}$ & $\begin{array}{c}C_{\text {exit }} \\
\text { (measured; } \\
\text { rounded to } \\
\text { nearest } 5 \mathrm{~g} \mathrm{~m}^{-} \\
3 \text { ) }\end{array}$ & $\begin{array}{c}m_{A C L} \\
\text { (eqn. 1) }\end{array}$ & $\begin{array}{l}\text { EN 378-1: } \\
2016 \text { (annex } \\
\text { C) }\end{array}$ & $\begin{array}{l}\text { IEC 60335-2- } \\
\text { 40: } 2015 \text { and } \\
\text { IEC 60335-2- } \\
\quad 89: 2019\end{array}$ \\
\hline & {$[\mathrm{m}]$} & {$[\mathrm{m}]$} & {$[\mathrm{m}]$} & {$[\mathrm{m}]$} & {$[\mathrm{m}]$} & {$[-]$} & {$\left[\mathrm{g} \mathrm{m}^{-3}\right]$} & {$[\mathrm{kg}]$} & {$[\mathrm{kg}]$} & {$[\mathrm{kg}]$} \\
\hline (i) wall AC & 2.0 & 2.0 & 2.3 & 2.2 & 2.0 & 0.54 & 150 & 1.026 & 0.380 & 0.419 \\
\hline (ii) cabinet $\mathrm{AC}$ & 0.0 & 0.1 & 0.9 & 0.4 & 0.95 & 0.57 & 130 & 0.515 & 0.380 & $0[0.15]^{*}$ \\
\hline (iii) floor $\mathrm{AC}$ & 0.2 & 0.3 & 0.55 & 0.3 & 0.65 & 0.57 & 130 & 0.352 & 0.380 & $0.042[0.15]^{*}$ \\
\hline (iv) window $\mathrm{AC}$ & 1.2 & 1.3 & 1.6 & 1.3 & 1.35 & 0.59 & 120 & 0.756 & 0.380 & 0.252 \\
\hline (v) ceiling $\mathrm{AC}$ & 2.5 & 2.5 & 2.8 & 2.5 & 2.65 & 0.53 & 160 & 1.322 & 0.380 & 0.524 \\
\hline (vi) serve-over & 0.0 & 0.6 & 1.4 & 0.4 & 0.4 & 0.44 & 95 & 0.167 & 0.380 & 0.238 \\
\hline (vii) gondola & 0.0 & 1.2 & 1.2 & 0.4 & 1.2 & 0.45 & 90 & 0.509 & 0.380 & 0.238 \\
\hline (viii) multi-deck & 0.0 & 0.4 & 2.2 & 0.3 & 0.9 & 0.47 & 75 & 0.405 & 0.380 & 0.238 \\
\hline
\end{tabular}

* According to these standards, if the ACL is less than $0.15 \mathrm{~kg}$ then the safety standards permit approx. $0.15 \mathrm{~kg}$. 


\section{Conclusions}

A new approach for estimating ACL for flammable refrigerants within closed rooms has been proposed, based on experimental measurements and observations with R290. In particular, this takes into account the general characteristics of RACHP enclosures and their installation heights, across the range of typically equipment used in various applications, such as refrigerated cabinet and AC IDU.

The method relies upon the estimation of refrigerant mass and how the openings affect the development of the layer volume height. Dimensional characteristics of the enclosure need to be known, that are used to determine $F_{L F L}$, based on known values of $C_{\text {exit }}$ of the enclosure. $C_{\text {exit }}$ is found to be largely a function of the internal volume of the enclosure, and the size and position of the openings in relation to the release position.

The analysis shows that the charge limits prescribed by various standards are in most cases overly restrictive. The proposed methodology and formulae, can be incorporated into the relevant RACHP safety standards (IEC 60335-2-40, IEC 60335-2-89, EN 378-1, ISO 5149-1), using experimentally determined or a nominal $C_{\text {exit }}$ for calculating $h^{*}$ and $F_{L F L}$, appropriate for the type of enclosure.

Changing the opening configurations can help to change $C_{\text {exit }}$ and $h^{*}$, and hence the ACL, thus enabling designers to adjust their equipment so that it poses a lower flammability risk or enables more refrigerant to be used without adversely affecting the level of flammability risk.

\section{Acknowledgement}

The authors would like to acknowledge project Proklima of the Deutsche Gesellschaft für Internationale Zusammenarbeit (GIZ) GmbH, HEAT GmbH, Deutsche Umwelthilfe e.V., ECOS, Environmental Investigation Agency International (EIA) and the EU LIFE FRONT Project for supporting this work.

\section{References}

1. Baines, W. D., Turner, J. S. 1969. Turbulent buoyant convection from a source in a confined region. J. Fluid Mech. 37, 51-80.

2. Cleaver, R. P., Marshall, M. R., Linden, P. F. 1994. The build-up of concentration within a single enclosed volume following a release of natural gas. J. Hazardous Materials, no. 36, pp. 209-226

3. Colbourne D., Suen K. O. 2016. R290 concentrations arising from leaks in commercial refrigeration cabinets. Proc. 12th IIR Gustav Lorentzen Conference, Édimbourg, United Kingdom.

4. Colbourne D., Suen K. O. 2018. Minimum airflow rates to dilute R290 concentrations arising from leaks in room air conditioners. Proc. 13th IIR Gustav Lorentzen Conference, Valencia, Spain.

5. Colbourne, D., K. O. Suen, T.-X. Li, I. Vince, A. Vonsild. 2020a. General framework for revising class A3 refrigerant charge limits - a discussion. Int. J. Refrig., https://doi.org/10.1016/j.ijrefrig.2020.04.024

6. Colbourne, D., Suen, K.O. 2003. Equipment design and installation features to disperse refrigerant releases in roomsPart 1: Experiments and Analysis. Int. J. Refrigeration, vol. 26, pp. 667-673. 
7. Colbourne, D., Oppelt, D., Pätzold, B., Mocholí, M. P., 2020b. Recommended leak hole size and mass flow rates by system and application characteristics. LIFE FRONT Final Report under EU Climate Action Programme, http://lifefront.eu/wp-content/uploads/2020/05/final_recommended-leak-hole-size-and-mass-flow-rates-by-systemand-application-characteristics-27052020.pdf.

8. EN 378-1: 2016. Refrigeration Systems and Heat Pumps - Environmental Requirements - Basic requirements, definitions, classification and selection criteria

9. IEC 60335-2-40: 2003+A2, 2009. Specification for safety of household and similar electrical appliances. Safety. Particular requirements for electrical heat pumps air-conditioners, and dehumidifiers.

10. European Commission, 2016. Report from the Commission on barriers posed by codes, standards and legislation to using climate-friendly technologies in the refrigeration, air conditioning, heat pumps and foam sectors. COM(2016) 749 final. Brussels, 30.11.2016.

11. Jabbour, T., Clodic, D., 2002. Ignition Tests of Flammable Refrigerant Leaks in Ventilated and Unventilated Rooms, Proc. 5th IIR Gustav-Lorentzen Conf., Guangzhou, China.

12. Kataoka, O., Yoshizawa, M., Hirakawa, T. 2000. Allowable Charge Calculation Method for Flammable Refrigerants. International Refrigeration and Air Conditioning Conference, Purdue, USA.

13. Li, T. 2014. Indoor leakage test for safety of R-290 split type room air conditioner. Int. J. Refrig. Vol. 40, pp. 380389.

14. Zhang, W., Yang, Z., Li, J., Ren, C-x., Lv, D., Wang, J., Zhang, X., Wu, W. Research on the flammability hazards of an air conditioner using refrigerant R-290. Int. J. Refrig., Vol. 36, No. 5, 2013 